\title{
El arrabal portuario de MÉrtola (Portugal): EL REGISTRO CERÁMICO ANDALUSÍ
}

\author{
SusAna Gómez MarTínez
}

Universidade do Algarve

\author{
Recibido: 06/04/2016 \\ Aceptado: 03/06/2016 \\ Revisado: 01/06/2016 \\ Publicado: 30/06/2016
}

\section{RESUMEN}

Las excavaciones de la Hospedaria Beira Rio y del Teatro Marques Duque de Mértola descubrieron restos del arrabal ribereño, un barrio bien organizado del siglo XII. Las casas no difieren de otras del mismo período, pero los vestigios y objetos encontrados en ellas permiten interpretar este espacio en un contexto portuario. Las cerámicas encontradas incluyen novedades en relación al repertorio de época omeya (ollas con escotadura, cazuelas carenadas y con "costillas" incipientes, botellas y jarritas de pasta blanca) y un nutrido conjunto de cerámicas de importación (cuerda seca total y parcial, y esgrafiado).

\section{Palabras Clave} ción.

\section{ABSTRACT}

The excavations at the Beira Rio Guest House and the Marques Duque Theatre have brought remains of Mértola's riverside settlement to light, a well organized 12 th century neighborhood. The houses do not differ from others in Mértola coming from the same period, but the remains and objects found within them allow this area to be inserted within the riverside context. The ceramics found include new items, different to the repertoire of the Umayyad era (saucepans and casseroles with a marked body, casseroles with rudimentary "ribs" and bottles and small vases made from white clay) and a set of imported ceramics ("cuerda seca" and Sgrafflato).

\section{KEYWORDS \\ islamic pottery; suburb; trade; production.}




\section{INTRODUCCIÓN}

Durante una buena parte del siglo XX, la investigación sobre el período de dominio musulmán en el actual territorio portugués adolecía de un fuerte atraso debido a prejuicios político-ideológicos (Fernandes y Macias, 2011: 167). La Revolución de los Claveles de 1974 abrió una nueva etapa en la arqueología medieval que se tradujo en un avance notable en el conocimiento del extremo occidental de al-Andalus en general y de la cerámica en particular (Inácio et alii, 2015 y Gómez et alii, 2015). En el avance de esta investigación, ha tenido un papel fundamental el estudio de colecciones bien contextualizadas mediante excavaciones arqueológicas que han permitido formalizar una secuencia cronoestratigráfica cada vez más precisa, aunque siguen existiendo algunas lagunas e imprecisiones, especialmente en lo que se refiere a los primeros siglos de dominio islámico en los que es casi imposible afinar una cronología usando solamente el registro cerámico. Una apreciación semejante puede hacerse sobre la cuestión de la procedencia de las diferentes producciones y de sus circuitos de distribución y consumo. El principal problema reside en el reducido número de centros alfareros excavados y las dificultades existentes para realizar estudios arqueométricos de envergadura que puedan suplir esta deficiencia.

Mértola es uno de los yacimientos en los que la investigación ha dado mayores frutos tanto en el conocimiento de la configuración urbana de la ciudad islámica como de la cerámica debido, por un lado, a la constancia de las investigaciones arqueológicas (a título de ejemplo cabe mencionar las tesis doctorales de Lopes, 2014 para la Antigüedad Tardía, y Macias, 2006 o Gómez, 2014 para el período andalusí) y, por otro lado, a las buenas condiciones del registro estratigráfico, bastante bien conservado en muchos puntos de la ciudad. A ello se une la riqueza de ese mismo registro derivada de la dinámica de la ciudad en el pasado, consecuencia lógica de las singulares condiciones geoestratégicas de su localización en el último punto navegable del río Guadiana. Este aspecto hizo de Mértola un nudo de comunicaciones entre las rutas marítimas del Mediterráneo y las vías terrestres del Alentejo durante la Antigüedad y la Edad Media (fig. 1).

A pesar de todo esto, los hallazgos se han visto muchas veces condicionados por la dinámica propia de la ciudad actual, restringiendo a terrenos no

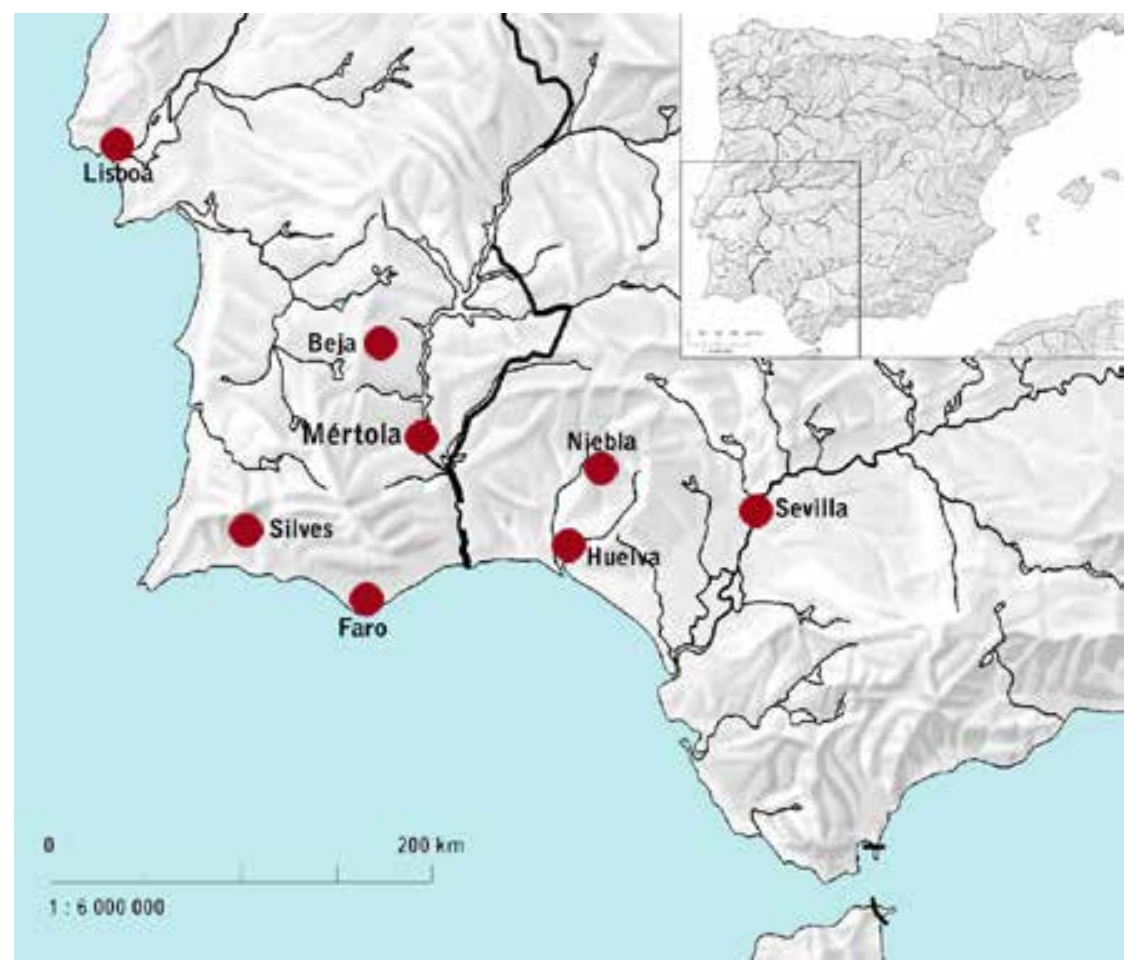

Fig. 1. Localización de Mértola en el contexto del suroeste peninsular. 
urbanizados las áreas de investigación sistemática y condicionando a las limitaciones de la arqueología preventiva zonas extensas del parcelario urbano.

A pesar de estas limitaciones del registro estratigráfico y por lo que se refiere a la cerámica, se han conseguido documentar contextos específicos que ayudan a comprender los fenómenos de producción y distribución y algunos procesos de transformación de sus dinámicas (Gómez, 2014). Uno de los casos de estudio más recientes e interesantes es el de los conjuntos encontrados en el arrabal portuario de la ciudad, especialmente por su cronología que se centra en el siglo XII. Este es un período estratigráficamente menos fiable en otros puntos de Mértola, pero de los que nos han llegado colecciones muy significativas provenientes de contextos revueltos, basureros y depósitos secundarios con alteraciones postdeposicionales, como en el caso del Criptopórtico-Cisterna de la Alcáçova do Castelo (Torres y Oliveira, 1987; Gómez, 2008).

Este arrabal (fig. 2), ha sido objeto de diversas intervenciones a lo largo de los últimos diez años (Gómez y Lopes, 2008; Lopes, Gómez y Rafael, 2012) que han revelado un dinamismo de los espacios portuarios que no debe sorprende a la luz del papel que la ciudad jugó en el contexto histórico del occidente de al-Andalus, especialmente a partir del siglo XI, cuando el afán de autonomía de las elites locales desembocó en la proclamación de la taifa independiente de Mértola gobernada por los Banū Tayfūr, una familia de origen muladí según unos (Viguera, 1994) y beréber según otros (Ewert, 1973: 9). Probablemente en 410 H. /1020 d.C. se oficializó lo que debía ser una situación de hecho ya al final del período amirí (Picard, 2000: 68). No obstante, el dominio de los Banū Tayfūr fue corto y Mértola es anexada al reino ‘abbādí de Sevilla en 436 H./1044 d.C. (Viguera, 1994, 111; Picard, 2000, 83; Khawli, 2001, 35).

El control de Sevilla se mantuvo también bajo el dominio almorávide hasta que, hacia mediados del siglo XII, el sufí Abū l-Qāsim Aḥmad b. al- Huṣayn Ibn Qasī encabezó la revuelta que elevó a Mértola a la posición de capital de un inestable y efímero reino independiente. Es, precisamente, durante los episodios bélicos que condujeron a la toma de la ciudad por Ibn Qasī cuando encontramos la única referencia escrita a este arrabal (Bosch Vilá, 1956, 287-288). El intento de mantener el control regional le llevó a solicitar la intervención almohade en una alianza que no respetó, desembocando en la toma de Mértola por estos últimos el 18 de yūmada primero de 542 d. H., es decir, 26 de junio de 1157 d.C. (Huici, 1959, 75-76; Ewert, 1973, 11; Khawli, 2001, 38).

¿Por qué razón fue tan importante el control Mértola para los sucesivos poderes del SO de alAndalus? Sin duda, sería de la mayor importancia su posición estratégica desde el punto de vista militar, aunque también económico y comercial. La aristocracia regional, con fuerte poder económico, tenía que controlar la plaza fuerte bisagra de los intercambios comerciales, situada más al norte relativamente a las rutas marítimas mediterráneas y con mejores vias de comunicación, pues combinaba medios terrestres y fluviales.

\section{Excavaciones en el Arrabal Portuario de}

\section{MÉrtola}

Durante la primera década de este siglo, sucesivas excavaciones arqueológicas de emergencia han dado a conocer el arrabal de Mértola (Gómez y Lopes, 2008; Gómez et alii, 2009), documentando una zona de viviendas, que tiene su auge durante las décadas centrales del siglo XII, y un sector artesanal de época almohade (fig. 3). La Hospedaria Beira Rio es el solar que ha facilitado más información. Situado al norte del recinto amurallado, justo sobre la cota máxima de las crecidas del Guadiana, en él se localizaron tres casas del siglo XII y, entre dos de ellas, una calle pavimentada en tierra batida, bajo la cual discurría una canalización de aguas pluviales y dos fosas detríticas (fig. 4). Las viviendas, siguiendo el modelo de la casa urbana andalusí, se estructuraban alrededor de un patio con el que comunicaban las otras habitaciones: zaguán, salón con alcoba, cocina y letrina conectada a una fosa negra que se abría en la calle contigua. Fueron construidas en tapial sobre un zócalo de mampostería y cubiertas con tejas de media caña. Algunas conservaban parte del estuco de las paredes con dibujos geométricos en almagre (Lopes, Gómez y Rafael, 2012).

Si bien la estructura de estas casas no difiere de las encontradas en otras zonas de la ciudad, varios hallazgos descubiertos en ellas y su localización junto al puerto fluvial, permiten interpretar estos espacios en un contexto portuario. Podemos asociar a actividades ribereñas un compás de hierro de carpintero de ribera, y varios barcos gravados en una laja que pavimentaba uno de los patios. También se documentan otras actividades agrícolas (una azada) $\mathrm{y}$ artesanales, especialmente las textiles atestigua- 


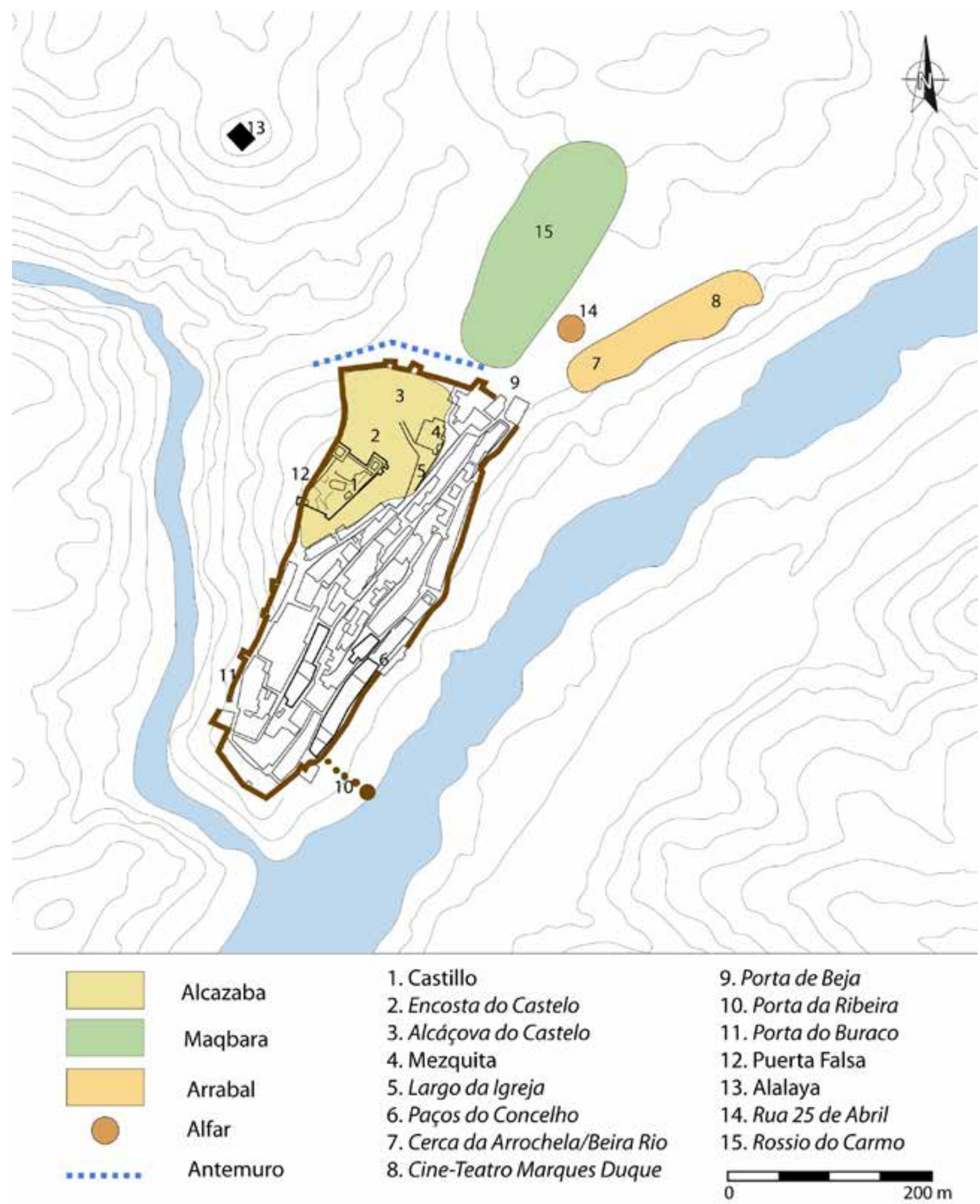

Fig. 2. Planta de Mértola y localización do arrabal portuario. 


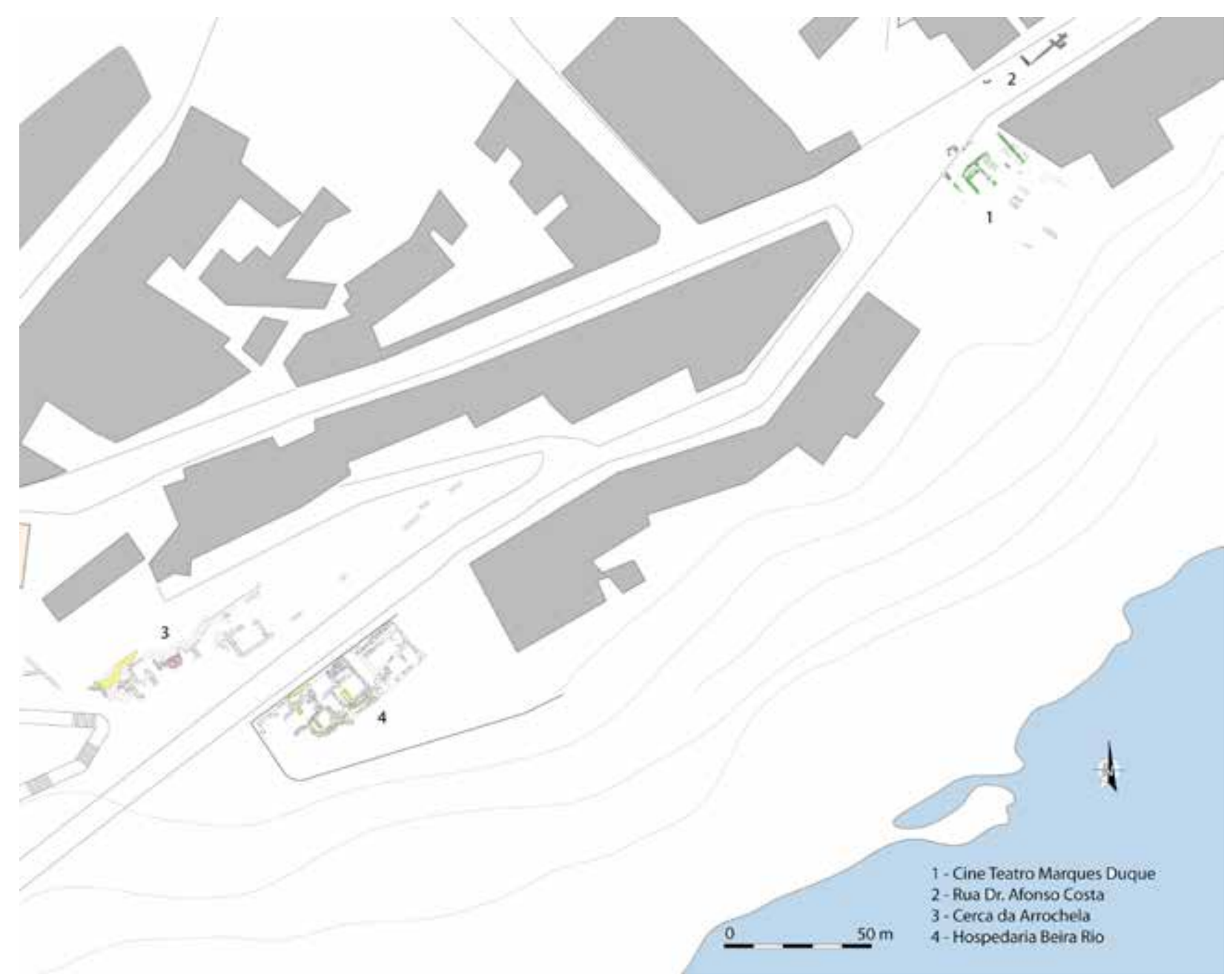

Fig. 3. Localización de hallazgos en el arrabal portuario.

das por objetos asociados al hilado (torres de rueca, puntas de huso y torteras), así como accesorios de uso personal (hebillas para cinturones y correas).

Cerca de este conjunto, pero en un contexto revuelto por obras de acondicionamiento de la calle de acceso al embarcadero actual, se encontraron ocho fragmentos de barras de horno de alfar (fig. 5). Todas ellas se realizaron con pastas rojizas, poco depuradas, con abundantes elementos no plásticos, entre los que resaltan gruesos gránulos de cuarzo, y se encuentran bastante ennegrecidas en su superficie por efecto de la prolongada presencia en el horno. Uno de los fragmentos presenta un goterón de vidriado verde (RDAC108/2004/0001). Se puede deducir de este hallazgo que el arrabal contaría también con instalaciones artesanales de fabricación de cerámica, que incluirían producciones vidriadas.
Tiene un especial interés para contextualizar la población del arrabal el hallazgo de cuatro cruces potenzadas gravadas en la solera de la entrada del salón de la casa 1 . Se trata de un indicio claro de cristianización de un espacio, que no pudo ocurrir después de la conquista de la ciudad por la Orden de Santiago en 1238. El abandono y destrucción de estas casas debe haber sucedido hacia la década de 70 u 80 del siglo XII, por lo menos cincuenta años antes de la llegada de los ejércitos portugueses. En este contexto plenamente almohade, el hallazgo atestigua la presencia de cristianos en un momento en el que la tolerancia para con estas comunidades habría disminuido fuertemente. Resta la duda, no obstante, de si se trataría de la comunidad mozárabe que persistía en el Garb al-Andalus en el siglo XII (Idrīsīi, 1968, 218-219), o de la creciente pre- 

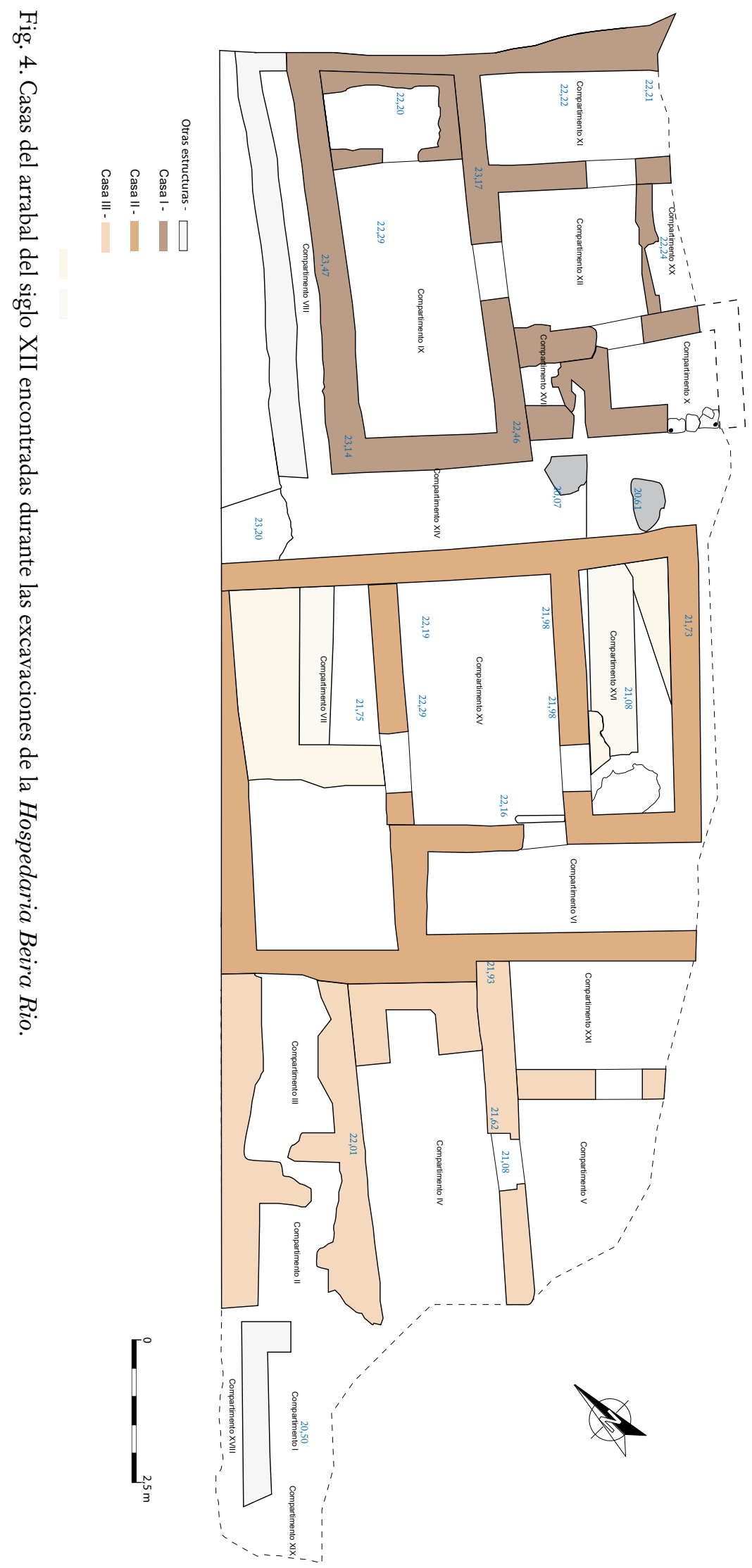

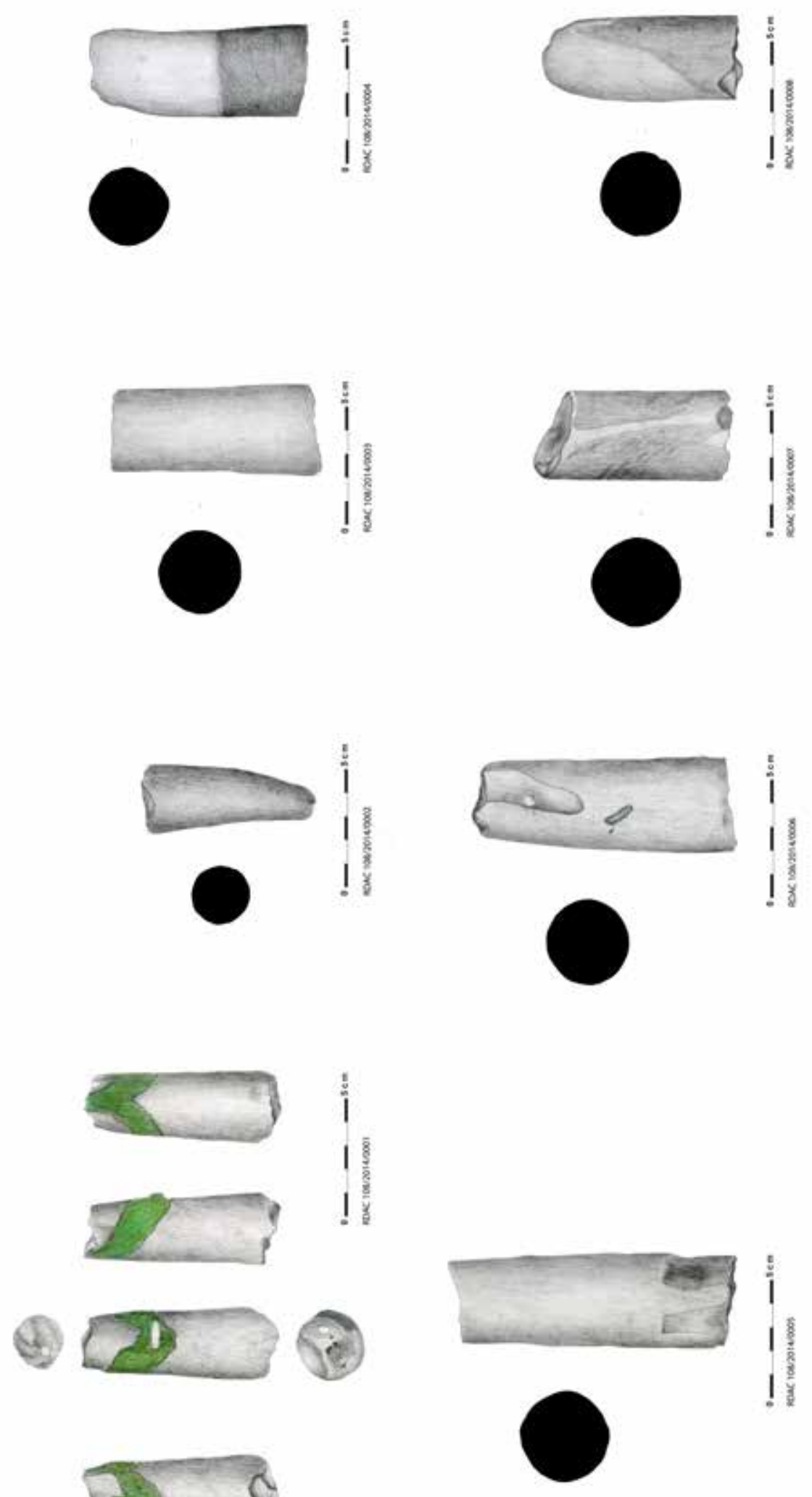

1
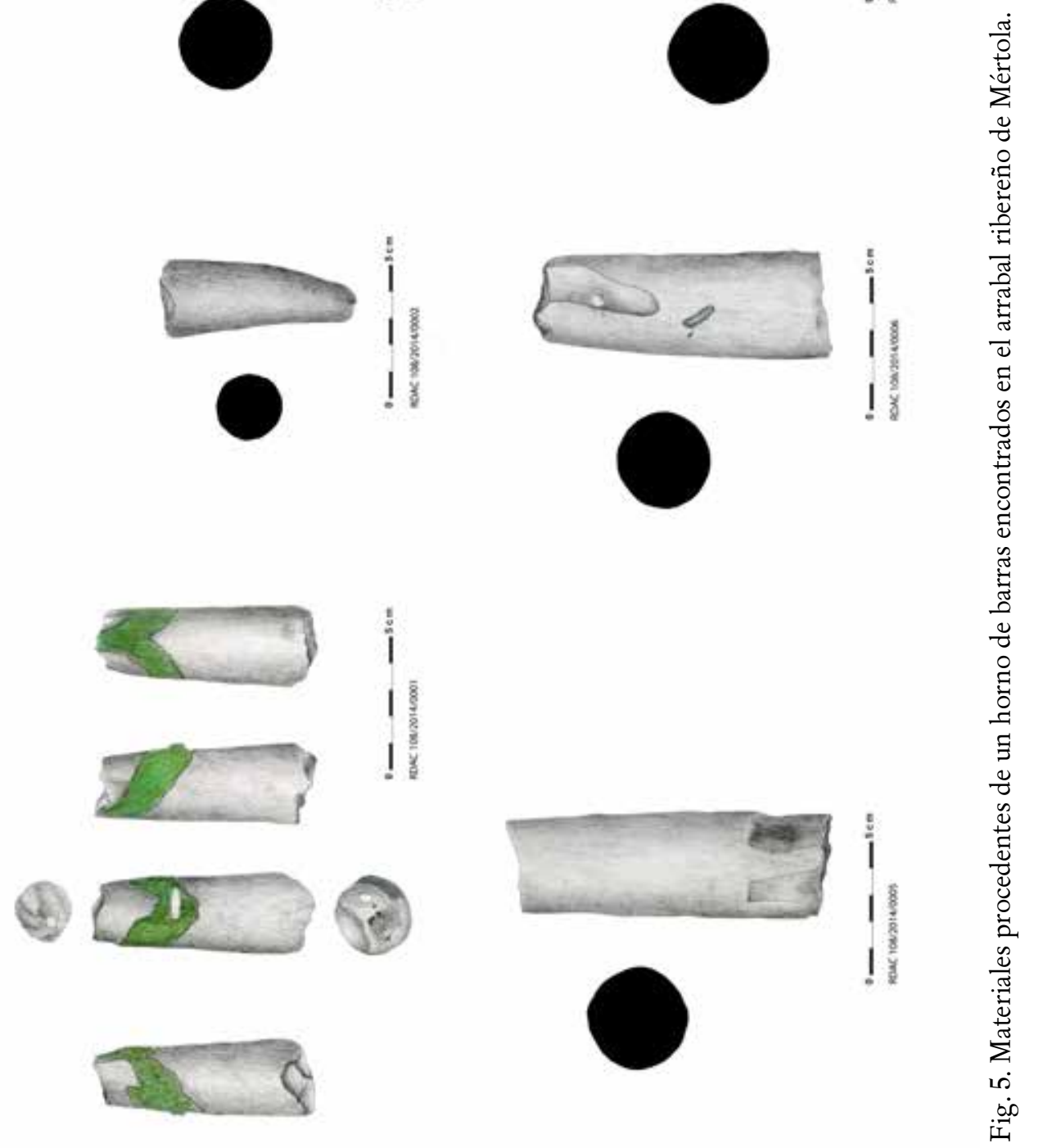

Revista ONOBA, 2016, No 04 
sencia de comerciantes cristianos en los puertos de al-Andalus (Constable, 1997: 118, 130).

\section{LA CERÁMICA}

El conjunto de piezas asociadas al abandono del barrio refleja el ajuar doméstico de las décadas centrales del siglo XII. En él se encuentran pervivencias del final de la época omeya junto a características formales y técnicas nuevas que se arraigarán más tarde, durante el período tardo-almohade.

La mayor parte del conjunto cerámico surge muy fragmentado, como es habitual. No obstante, dos contextos de relleno de dos fosas negras contenían piezas bastante completas que nos han permitido tener una noción más apurada de los perfiles de los objetos en uso en el arrabal.

\subsection{Vajilla de almacenamiento y transporte}

Por lo que refiere a la vajilla de almacenamiento y transporte, se documentan tinajas, tapaderas de tinaja y cántaras de pastas rojizas.

Las tinajas presentan cuellos cilíndricos y bordes de sección cuadrangular con un grueso cordón digitado en el contacto entre el cuello y la panza (HBR-0198, fig. 6.1.). Se trata de formas y técnicas ornamentales de raigambre omeya que conviven con tinajas estampilladas con motivos epigráficos (HBR-0228 fig. 6.2), arquitectónicos y fitomórficos almohades, en algunos casos con vidriado verde. En un caso (HBR-0212), igualmente vidriado en verde, la matriz era de grandes dimensiones aproximándose más a motivos a molde que a temas estampillados (fig. 7). A estas últimas piezas, de la segunda mitad del siglo XII, se unen tapaderas también estampilladas con motivos geométricos y con vidriado verde parcial (HBR-0216; fig. 6.3).

Las cántaras también siguen formas sencillas de tradición omeya con motivos ornamentales formados por cordones digitados y pintura blanca (fig. 6.4). Este tipo parece anteceder a las jarras producidas en el horno tardo-almohade de la ciudad y que se constata en los niveles de abandono, hacia el año 1238, del barrio de la Alcáçova do Castelo (Gómez, 2014).

\subsection{Loza de cocina}

En la cerámica de cocina, surgen formas ausentes hasta el siglo XII. Por un lado, encontramos ollas globulares con escotadura en el hombro, cuerpo estriado y dos asas en la panza, fabricadas con pastas marrones, que en algunos casos presentan rastros de pintura blanca (HBR-0189, fig. 8.1). Se trata de
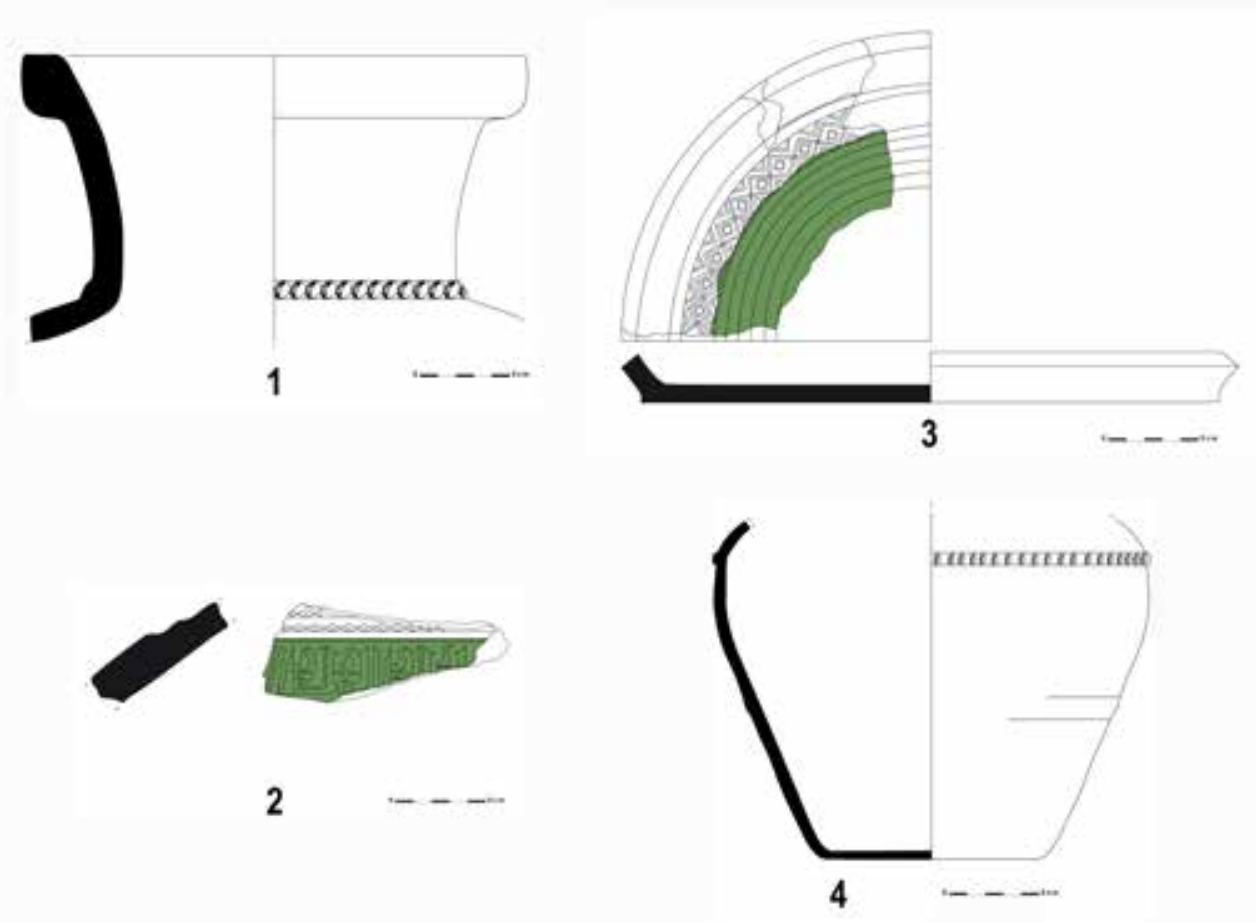

Fig. 6. Formas de almacenamiento y transporte. 
una forma con paralelos formales en las ollas de la meseta de época omeya (Retuerce, 1998) pero que sólo vamos a documentar en el suroeste peninsular a partir del siglo XII.

Otra forma desconocida anteriormente y que, hasta ahora, sólo se documenta en estos contextos estratigráficos del arrabal, es la olla globular sin cuello ni base marcadas y arranque, junto al fondo, de dos asas cuyo perfil desconocemos. Presenta pastas rojizas y un acabado cuidado con un engobe uniforme (HBR-0191, fig. 8.2.).

Una tercera forma de olla presenta cuello cilíndrico bajo y curvo, cuerpo ligeramente piriforme, con dos asas y base convexa. Las pastas son rojizas con alternancia en la cocción que concluyó con una fase oxidante irregular. Le fueron aplicados motivos ornamentales circulares de pintura blanca (HBR-0200, fig. 8.3). Se trata de una olla con raíces en formas ya conocidas en Mértola del siglo XI (Marmita 4B y C, Gómez, 2014, 107) pero que evoluciona hacia un perfil más esbelto.

Una forma bitroncocónica, semejante a un tipo de taza fechado en el siglo XI (Taza 2, Gómez, 2014: 149), aparece con fuertes marcas de fuego que indican su uso como olla. El ejemplar documentado más completo tiene base convexa y conserva un asa vertical de sección oval con nervadura y apéndice superior. Presenta pasta marrón y trazos verticales de pintura blanca (HBR-0190, fig. 8.4).

Por lo que se refiere a las cazuelas, encontramos una mayor diversidad que en el período anterior. Pueden considerarse de tradición omeya las de borde exvasado curvo (HBR-0202, fig. 9.1.), con cuerpo de tendencia hemisférica y base convexa, que aparecen con pastas parduzcas y en un caso con un cuidado acabado bruñido y motivos semicirculares en interior del borde (HBR-0222, fig. 9.2.). Aparecen ahora dos formas nuevas: por un lado, las cazuelas carenadas, con base convexa y asa entre el borde y la base, y pastas rojizas o parduzcas, ocasionalmente con motivos curvos pintados en blanco en el borde (HBR-0223, fig. 9.3.); y por el otro la muy conocida cazuela de costillas, todavía incipientes y en reducido número, con pastas marrones (HBR-0224, fig. 10.1).

Un fragmento con gruesas perforaciones, que no se había documentado antes en Mértola, podría corresponder a una quesera o cuzcuzera (HBR0213, fig. 10.2). La presencia de formas semejantes en contextos rurales emirales del Alentejo (Marques et alii, 2014) nos hace suponer un uso más relacio-

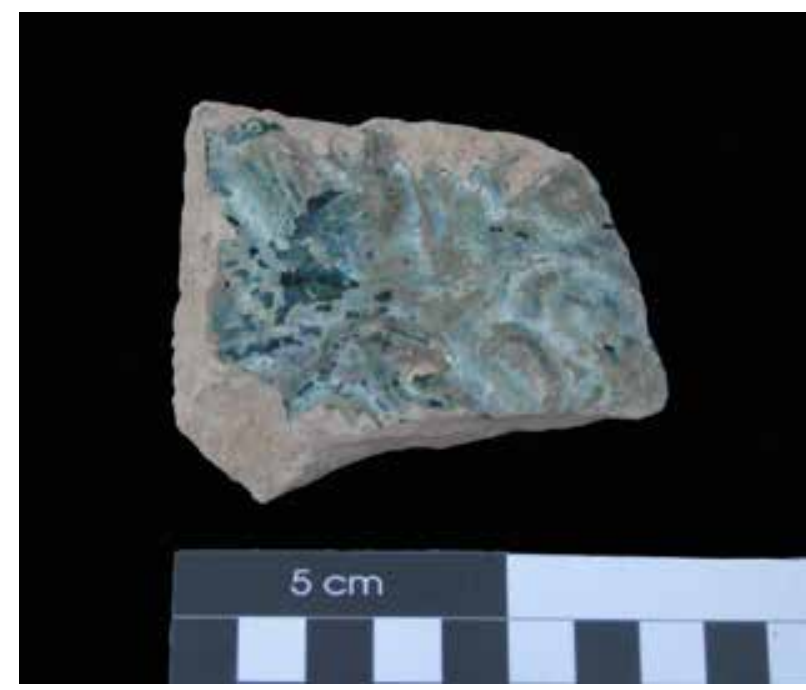

Fig. 7. Fragmento de tinaja con motivo estampillado/ molde y vidriado verde (HBR-0212).
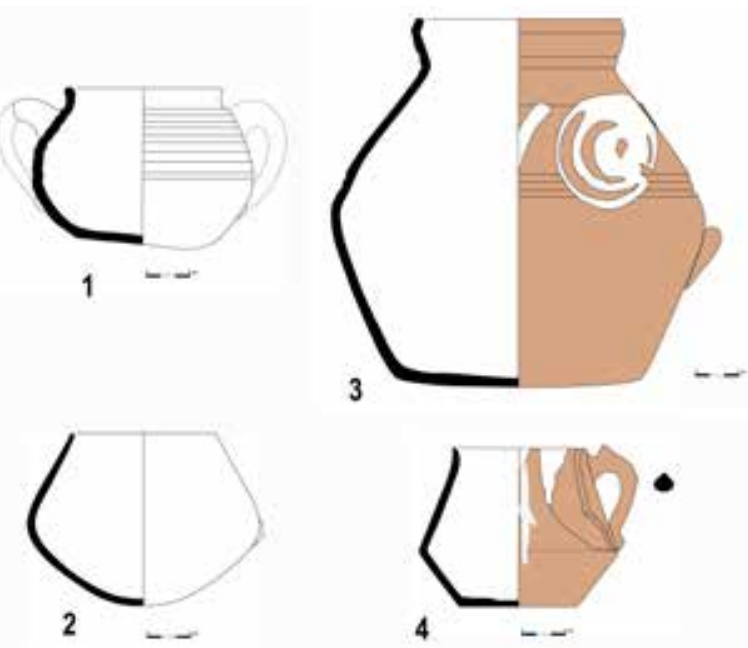

Fig. 8. Loza de cocina. Ollas.
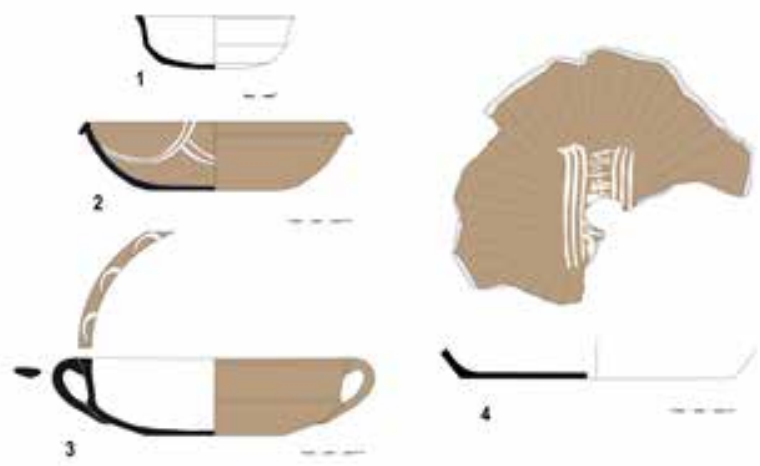

Fig. 9. Loza de cocina. Cazuelas. 


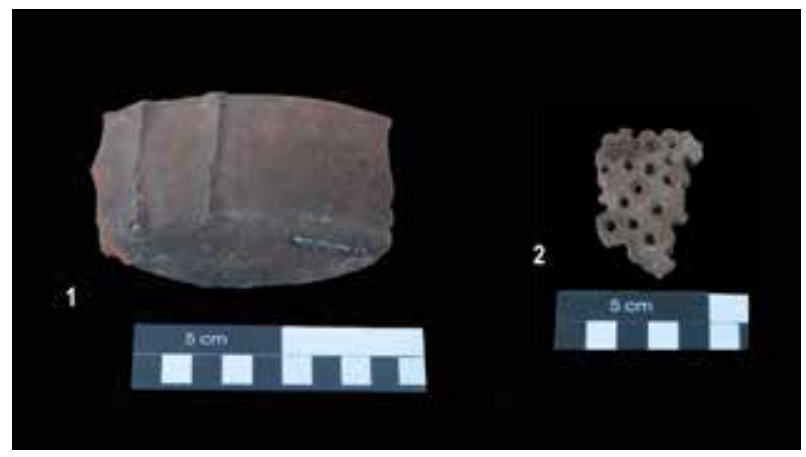

Fig. 10. Loza de cocina. Cazuela de costillas y quesera o cuzcuzera.

nado con la transformación de alimentos más, que con la receta tradicional norteafricana.

También tienen marcas de fuego los alcadafes de grandes dimensiones y base plana, con paredes bastante delgadas si tenemos en cuenta el tamaño de la pieza, que presentan su interior bruñido y con motivos de pintura blanca (HBR-0199, fig. 9.4).

\subsection{Vajilla de mesa}

Por lo que se refiere a las formas de mesa, la diversidad formal y técnica es mayor que en el repertorio cerámico de época omeya. Encontramos una gran variedad de jarras, jarros, ataifores, redomas y limetas.

Las jarritas, de tradición omeya, de base convexa, cuerpo globular y cuello cilíndrico alto y
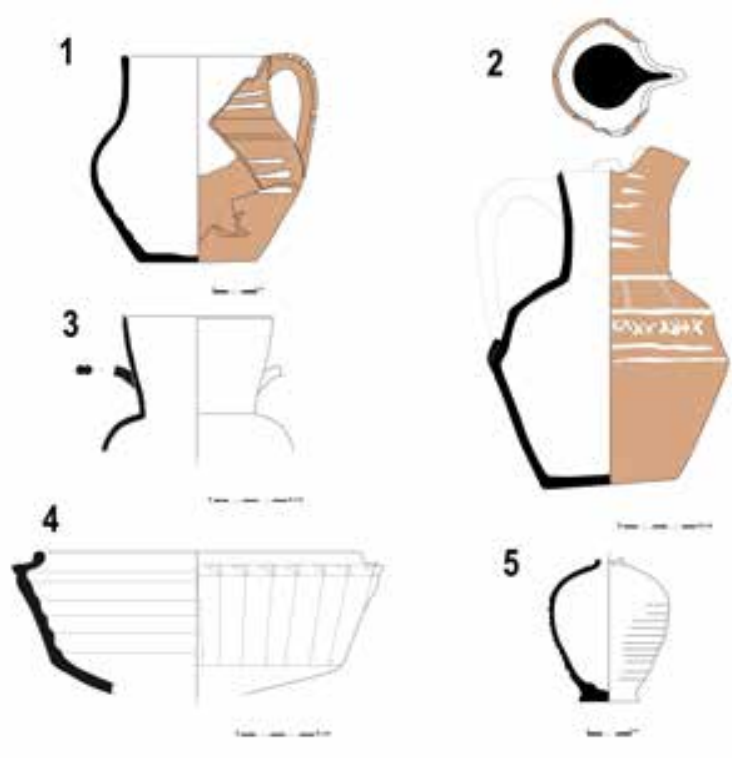

Fig. 11. Vajilla de mesa. ancho con dos asas verticales, aparecen con pastas rojizas y pueden presentar pintura blanca de trazos horizontales (HBR-0203, fig. 11.1.).

A parecen formas nuevas que evolucionan a partir de tipos de época omeya, como el jarro de base convexa, cuerpo con doble carena, cuello cilíndrico alto y boca trilobulada con pico de pellizco, que surge con motivos pintados en blanco combinando reticulados con temas fitomórficos (HBR-0187, fig. 11.2).

A estas formas, cuyas pastas y técnicas de fabricación nos permiten considerar como producciones locales, hay que añadir otras formas nuevas, con técnicas poco habituales y paralelos en otras regiones de al-Andalus, que nos llevan a suponer una proveniencia exógena. Se trata, por un lado, de piezas de pasta blanca: jarritas de paredes finas con cuerpo globular, cuello troncocónico invertido y dos asas (HBR-0226, fig. 11.3), trípodes con escisiones verticales (HBR-0225, fig. 11.4) y limetas de cuerpo estriado y base plana (HBR-0201, fig. 11.5). La ausencia de análisis arqueométricos nos lleva a ser cautelosos en relación a cuál sería el taller de procedencia de estas piezas ya que son formas que van estar presentes en muchas localidades del sudoeste de al-Andalus. El trípode con excisiones verticales y la jarrita globular de cuello troncocónico invertido surgen en contexto de alfar en Córdoba (Molina y Salinas, 2013, 184 y fig. 4), pero son muy frecuentes también en casi todas las ciudades almohades del sudoeste como por ejemplo ejemplo

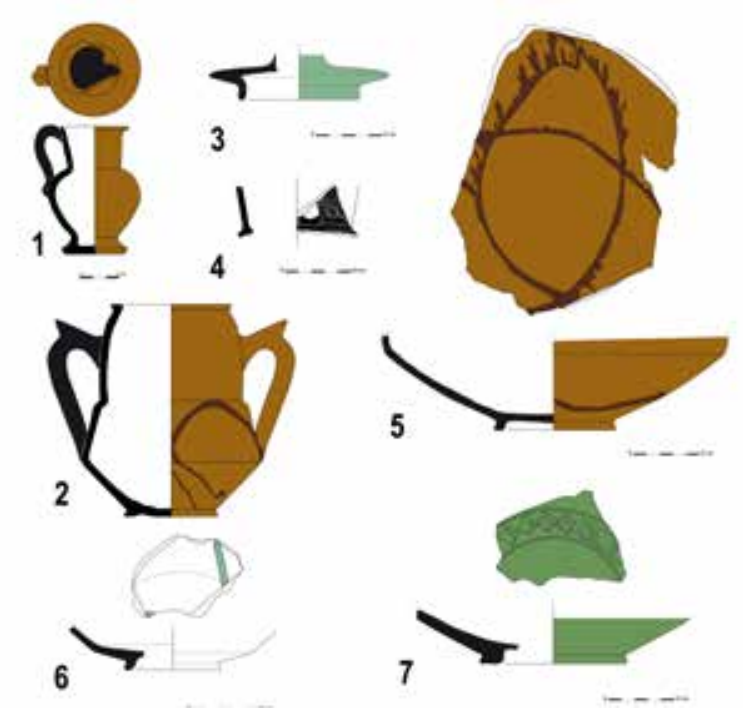

Fig. 12. Vajilla de mesa vidriada. 
en Silves (Gomes y Gomes, 2001, no 117), Jerez de la Frontera (Fernández, 1987: 457 y fig. 6), Cádiz (Cavilla, 2005) o la Catedral de Sevilla (Huarte y Lafuente, 2002: 414).

Por otro lado, aparecen ahora nuevas formas de mesa vidriadas: el jarrito revestido de vidriado melado con base anular maciza, cuerpo globular, cuello cilíndrico bastante estrecho, asa vertical y pico de pellizco (HBR-0188, fig. 12.1), y la jarra de cuello troncocónico curvo, cuerpo bitroncocónico, base con anillo indicado y dos asas verticales con apéndice superior que se reviste de vidriado melado con trazos negros de manganeso (HBR-0186, fig. 12.2.). También es nueva la tapadera de cuerpo aproximadamente troncocónico sobre anillo para encajar en una jarra u orza (HBR-0218, fig. 12.3).

Un tipo de pieza importada, raro en nuestra región, es la jarrita de cuerpo globular y cuello troncocónico invertido con motivos esgrafiados sobre pintura negra (HBR-0210, fig. 12.4), típicos del sudeste de al-Andalus, (a título de ejemplo mencionaremos Navarro, 1986a; Flores, Muñoz y Lirola, 1999).

Un fragmento de jarra (HBR-0104) presenta vidriado blanco con reflejo metálico sobre motivos a molde, un tipo de producción bien documentada en Mértola cuyo posible origen local se mantiene en duda (Gómez, 2014) sobre todo a raíz de los hallazgos de moldes compatibles con estas formas en Almería (Flores, 2011) y Calatrava (Retuerce, Hervás y De Juan, 2009).

Los ataifores, en su mayoría vidriados, también aparecen con una mayor diversidad técnica y cambios formales. Encontramos ataifores con anillos de solero proporcionalmente de menor diámetro, más altos y de sección diagonal en relación al repertorio omeya, que pueden aparecer con la combinación de fondo melado y arcos secantes en manganeso (HBR-0219, fig. 12.5), o con vidriado blanco, ocasionalmente con trazos en verde (HBR-0217, fig. 12.6). En algunos ejemplares el cuerpo es bitroncocónico y aparece vidriado verde con estampillas de carácter zoomórfico bajo la cubierta (HBR-0227, fig. 12.7), combinación que será muy frecuente en época tardo-almohade. También encontramos ataifores hemisféricos vidriados en melado con motivo de cordón de la eternidad geométrico en el exterior, claramente encuadrables en una cronología almohade (HBR-0212b, fig. 13).

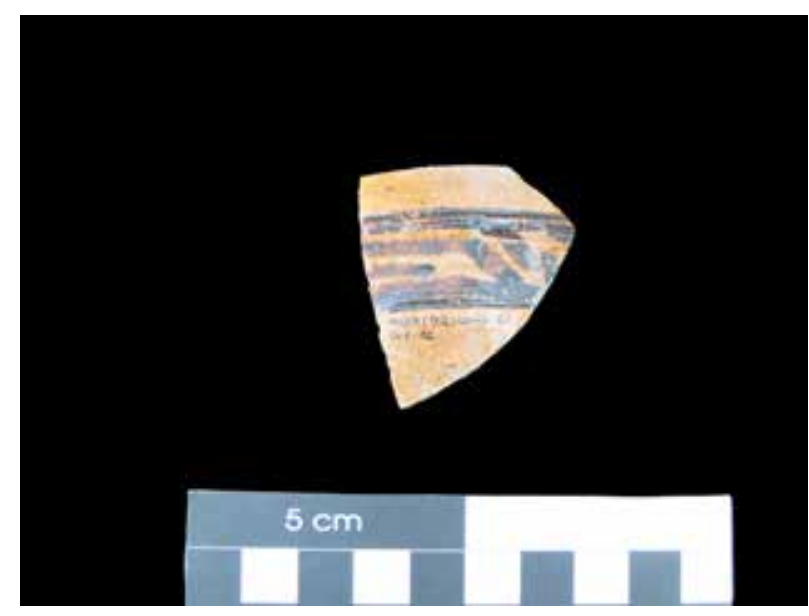

Fig. 13. Ataifor vidriado en melado con motivo de cordón de la eternidad geométrico.

\subsection{Objetos de iluminación, rituales y sim-} bólicos

Encontramos varios ejemplares de candil que corresponde al candil de piquera facetada que enlaza abruptamente con el cuerpo. La pasta es clara $\mathrm{y}$ suele poseer dos goterones vidriados en melado en el enlace entre piquera y depósito (HBR-0214, fig. 14.1).

Es ejemplar único un fragmento de pila de abluciones de planta rectangular y cuerpo troncopiramidal invertido, revestido en su interior con vidriado monocromo verde y una roseta estampillada bajo cubierta (HBR-0215, fig. 14.2). Ambos son objetos profusamente documentados en el sudoeste de al-Andalus sin que, hasta el momento, se pueda definir un centro productor específico para ninguno de los dos.

\subsection{Vajilla de cuerda seca}

Constatamos un porcentaje de cerámica de cuerda seca total más elevado que en otros contextos de vivienda de Mértola. Las características técnicas (pastas claras y porosas, ligeramente friables, diferentes de las constatadas en las producciones locales) y estilísticas (formas y motivos muy semejantes a los constatados en los centros productores del SE de al-Andalus, especialmente Almería) indican que se trataría de objetos importados (un análisis mucho más detallado de esta cuestión en Déléry, 2006, ver también Flores, Muñoz y Lirola, 1999). Desgraciadamente, el estado de conservación de los vidriados es bastante malo, degradado y con abundantes concreciones que dificultan, en algunos ca- 

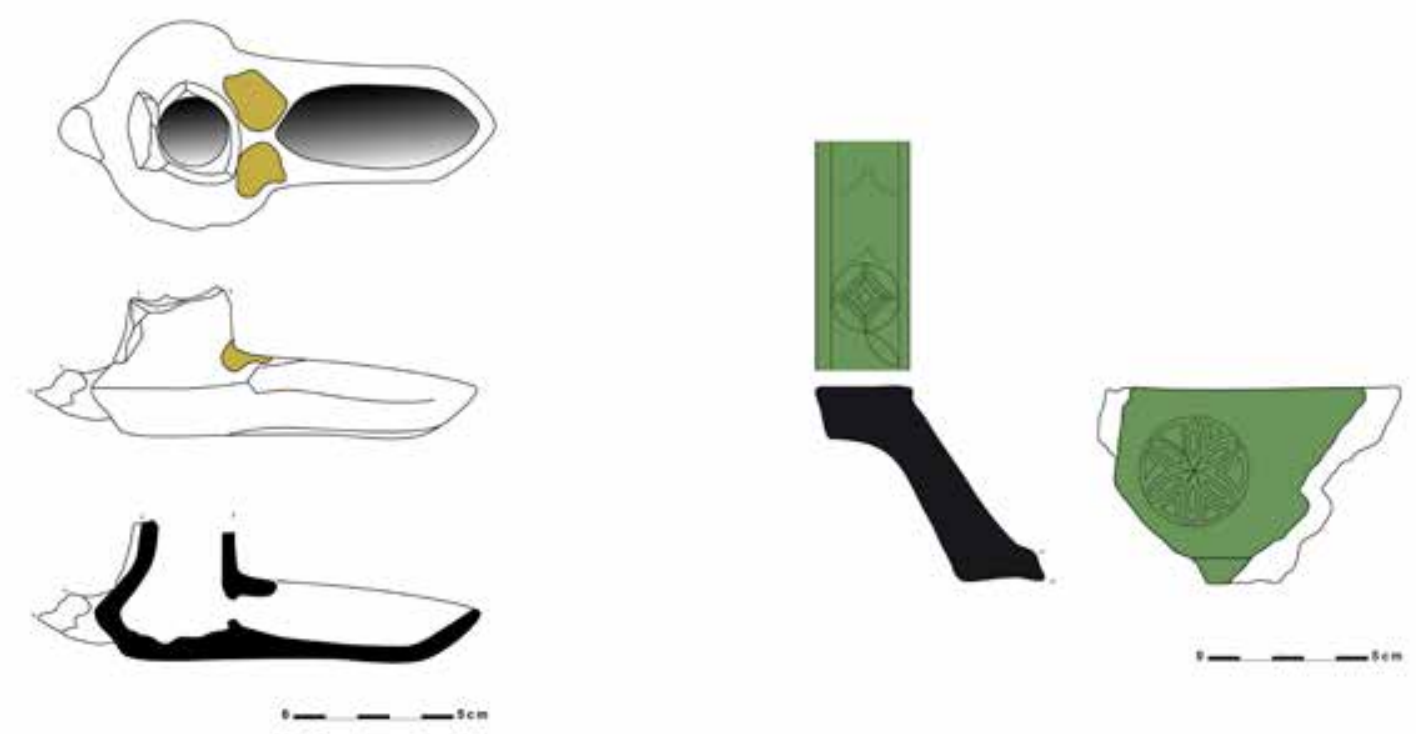

Fig. 14. Candil de piquera facetado y pila de abluciones de planta rectangular.

sos, la identificación de los colores originales. Esto, unido a la fragmentación de la muestra, impide determinar el motivo ornamental.

La variedad formal del conjunto es considerable (fig. 16). Encontramos ataifores hemisféricos de borde exvasado curvo, ocasionalmente con el labio biselado o de perfil semicircular, aunque el más frecuente es el labio de perfil triangular (HBR-0185 fig. 15.1). Los fondos suelen ser convexos y tienen siempre anillo de solero diagonal o vertical bastante alto (HBR-0060 fig. 15.3). El otro tipo de ataifor dominante es el de perfil acusadamente carenado, de borde vertical con labio de perfil semicircular o triangular (HBR-0134 fig. 15.2).

Encontramos un número considerable de tapaderas que aparecen con cuerpo hemisférico, que podrían ser usadas también como ataifores. Otras, también hemisféricas, poseen una moldura sobresaliente para encajar en otra pieza (HBR-0088 fig. 15.4). Un tercer tipo posee perfil troncocónico invertido sobre un anillo de encaje en otro recipiente, seguramente una redoma u orza (HBR-0119 fig. 15.5).

Son escasos y muy fragmentados los ejemplares de limetas o redomas y de jarritas (la fragmentación de la muestra impide reconocer el tipo exacto). Por último, hay que referir una extraña forma de base cilíndrica con fondo perforado (HBR-0139 fig. 15.6) cuya funcionalidad nos escapa.
Exceptuando esta última pieza, los tipos presentes en la Hospedaria Beira Rio no difieren de los ya documentados en la Alcáçova de Mértola, con paralelos bastante exactos en Almería (Flores, $\mathrm{Mu}-$ ñoz y Lirola, 1999), especialmente la tapadera con moldura sobresaliente para encaje.

Dada la fragmentación de la muestra, rara vez se distingue la combinación cromática completa, pero es posible reconocer que, por regla general, utiliza en el anverso, el blanco para definir el fondo del tema ornamental rellenándose el cuerpo de los motivos con combinaciones de melado, verde y negro de manganeso. El reverso de las piezas se recubre de vidriado melado o melado verdoso.

Un único ataifor combina a cuerda seca total con el estampillado de tema fitomórfico bajo cubierta (HBR-0178). Se trata de un fragmento de ataifor carenado, de pasta anaranjada bastante bien depurada, en el que apenas reconocemos vidriado melado y verde en el anverso (este último cubre las estampillas) y melado en el reverso.

Los motivos ornamentales también son variados aunque no tanto como los que reconocemos en el conjunto de cuerda seca encontrado en otros puntos de Mértola. Dominan los motivos fitomórficos, dentro de los cuales el tema de la roseta geométrica formando una flor de loto en perspectiva cenital es el más abundante (identificado en trece ejemplares). Ejemplos idénticos a estas piezas pueden ser 

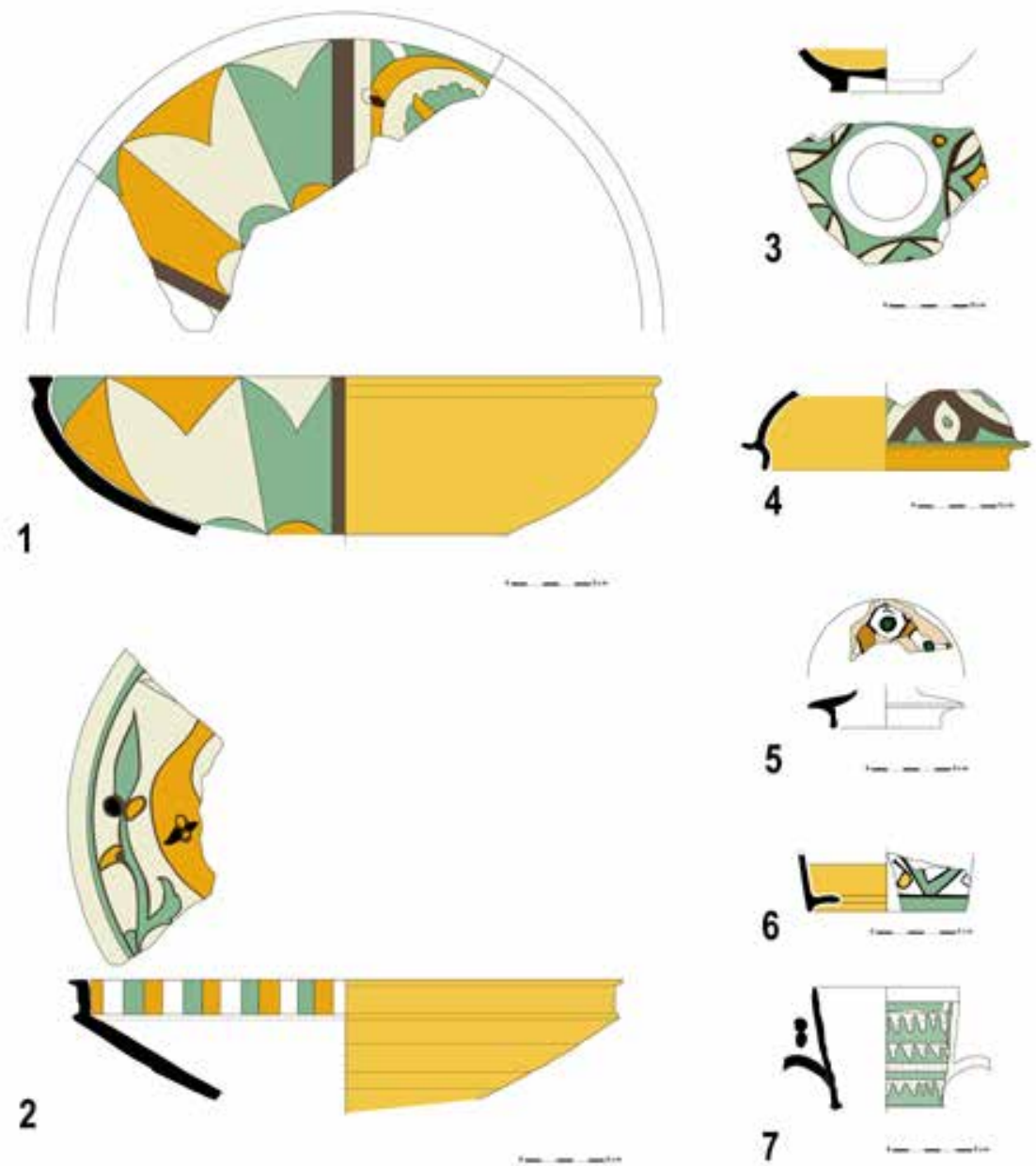

Fig. 15. Vajilla de mesa en cuerda seca de la Hospedaria Veira Rio.

\section{Formas de cuerda seca total}

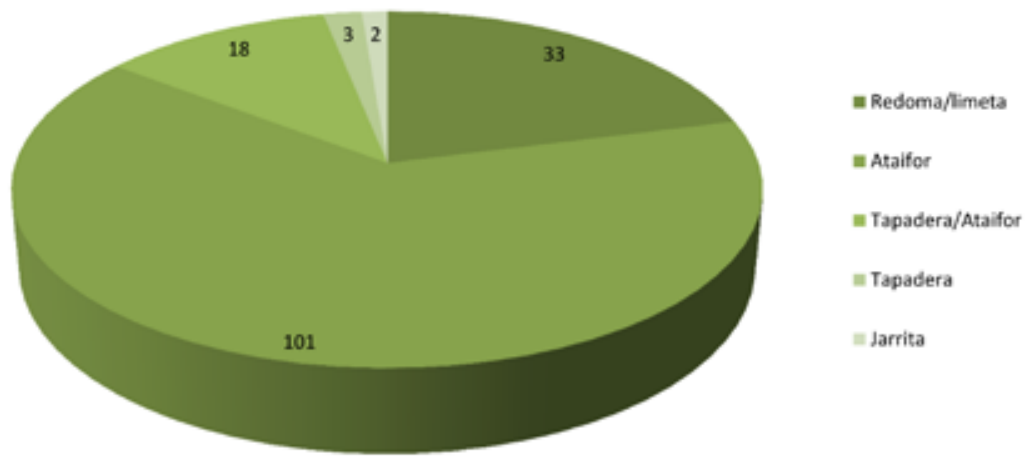

Fig. 16. Formas funcionales en la cuerda seca total de la Hospedaria Veira Rio. 
encontrados en diversos puertos del Mediterráneo Occidental, como por ejemplo en la Alcazaba de Málaga (Puertas, 1989, 19, fig. 16 y lam. 6), en Palma de Mallorca (Rosselló Bordoy, 1978, 116), en Pisa (Berti y Tongiorgi, 1981, 163-164 y tav. LIV ) y en Ceuta (Fernández, 1988, II, 142). Un estudio de conjunto se puede encontrar en Déléry (2006: 253 y sig.) que concluye que este motivo surge en tres tipos formales y con cuatro estilos ornamentales directamente relacionados con ellos, permitiendo afirmar que varios centros producirían esta variante simultáneamente, entre los cuales Granada y Almería. Se destaca en nuestro conjunto de la Hospedaria Beira Rio un caso, único, en el que el esquema radial cuatripartito de la roseta alterna con una palmeta (HBR-0185).

El capullo de flor de loto en perfil o formando un esquema triangular también es muy abundante tanto en formas abiertas como en cerradas. En algunos fragmentos de mayores dimensiones, que permiten identificar el tema ornamental de forma más completa, los motivos fitomórficos surgen como decoración secundaria que rellena los espacios vacíos dejados por el motivo principal (HBR-0162). Los motivos zoomorfos no son muy frecuentes (tres ejemplares) y rara vez lo suficientemente completos como para poder identificar de qué animal se trata. Los motivos geométricos aparecen como complemento de un tema principal de otra naturaleza y pueden ser triángulos dentados, o barras verticales alternando los colores de la composición cromática en el interior de los bordes de ataifor carenado. Hasta ahora no hemos podido identificar temas epigráficos, aunque algunos fragmentos de motivo ornamental indeterminado podrían pertenecer a este grupo.

La cuerda seca parcial es menos abundante (19 piezas frente a 157 de cuerda seca total) y adolece de los mismos problemas de fragmentación y deficiente estado de conservación de los vidriados que encontrábamos en la cuerda seca total. Desde el punto de vista formal, se destacan las jarritas de cuello troncocónico invertido, que pueden aparecer con filtro apenas identificado por el arranque del mismo (HBR-0001, fig. 15.7). Los motivos, muy fragmentados $y$, por lo tanto, de difícil identificación, son las bandas punteadas y las bandas dentadas, que conocemos bien de otras piezas más completas encontradas en otros contextos de Mértola (Gómez, 2014: 243-246). La dispersión de estas jarritas se extiende por todo el sur de al-
Andalus (una síntesis en Déléry, 2006); a título de ejemplo, la encontramos en Denia, Alcoy (Azuar, 1989, 329), Palma de Mallorca (Rosselló Bordoy, 1978, 119), Lorca (Navarro, 1986b, 50 y 128), Murcia (Navarro, 1986b, 153 y 240-241), Beca (Cavilla, 1992, 140) y Cádiz (Cavilla, 2005). También se encuentran piezas de cuerda seca parcial con estos temas en el Norte de África como por ejemplo en Ceuta (Fernández, 1988, 149).

Se trata, por lo tanto, de un conjunto muy homogéneo desde todos los puntos de vista que, a pesar de su gran difusión por el Mediterráneo Occidental, parece proceder de un único centro de producción que, a la luz de los conocimientos actuales, podría ser Almería.

\section{CONCLUSIONES}

El conjunto cerámico del arrabal portuario de Mértola aporta una apreciable clarificación en lo que se refiere al repertorio cerámico de Mértola del siglo XII, con una cronología que nos arriesgaríamos a centrar, grosso modo, entre el 1130 y el 1180. Su carácter "transicional" queda patente en la superveniencia de algunas formas de raigambre omeya como la jarrita globular de cuello cilíndrico, la cazuela hemisférica de fondo convexo, o la tinaja de cuello cilíndrico.

Los aspectos innovadores surgen tanto en el plano formal como en el plano técnico. En el formal, encontramos tipos raros que rápidamente evolucionarán para otras formas en época tardo-almohade, como la olla de forma globular sin cuello o fondo marcados, que más tarde definirá mejor el fondo (Gómez, 2014, tipo 6C). La semejanza con algunas de las formas de época almorávide encontradas en Albalat (Gilotte, Cáceres y de Juan, 2015) como la olla y la cazuela de escotadura, los ataifores levemente carenados o el candil de piquera fuertemente facetada, nos permiten retrotraer la cronología del conjunto a un momento anterior a la presencia almohade.

Resulta difícil determinar el origen de estas modificaciones, especialmente por el escaso conocimiento que tenemos de las vajillas norteafricanas, aunque una buena parte de esta evolución parece derivar de la dinámica de los talleres andalusíes. En el caso concreto de la olla de escotadura, su presencia fuera de la Marca Media de al-Andalus, donde tomó carta de naturaleza en época omeya, pudo estar relacionada con la emigración de alfareros tras la conquista cristiana de una buena parte de la $\mathrm{Me}-$ 
seta, primero en las últimas décadas del siglo XI y después, progresivamente, a lo largo siglo XII.

Este repertorio formal evolucionará en época tardo-almohade para una mayor diversidad tipológica, si bien están ya presentes todas las técnicas ornamentales que encontraremos en la primera mitad del siglo XIII.

Por lo que se refiere al aspecto técnico, uno de los elementos a señalar es la presencia más destacada de piezas de pastas claras, muchas veces con paredes muy delgadas. Las cocciones son más homogéneas que en la etapa omeya en la que era mucho más frecuente la cocción alternando a oxidación y la reducción.

Pero lo que más destaca es la mayor profusión del vidriado y las diversas combinaciones cromáticas con que surge: vidriados monocromos melados, blancos y verdes; bicromos en melado y negro y blanco y verde; cuerda seca total y parcial y reflejo metálico. No obstante, constatamos la ausencia dentro de este conjunto de loza de cocina vidriada. A pesar de la poca fiabilidad de este argumento por falta de evidencias, podemos especular con la hipótesis de que la introducción de cerámica de cocina vidriada se haya producido más tarde, en época tardo-almohade, únicamente a partir del inicio del siglo XIII.

Podemos, así, concluir que durante las décadas centrales del siglo XII se introducen las principales innovaciones formales y combinaciones técnicas en la ornamentación que se afianzarán más tarde, evolucionando para la consolidación de formas y técnicas que se transforman en modelos estandarizados producidos y distribuidos de forma generalizada por todo el sur de al-Andalus.

La abundancia de un tipo específico de cerámica que consideramos importada, la cuerda seca, nos incita a pensar que en el arrabal pudo instalarse un almacén de objetos provenientes del comercio marítimo-fluvial. La presencia de una buena parte de los fragmentos de cuerda seca en los contextos de construcción/reparación de las viviendas del arrabal, permiten suponer que algunos de los objetos procedentes de ese comercio, eventualmente rotos durante el viaje pudieron ser vertidos en las inmediaciones de la zona portuaria y utilizarse como relleno para nivelamiento de pisos y relleno de zanjas.

Se trata, en conclusión, de un conjunto bastante diversificado desde el punto de vista formal y con una variedad técnica difícil de explicar fuera del contexto portuario de hallazgo.
Todavía existen zonas no urbanizadas en la zona en la que se ubicaba el arrabal portuario de Mértola, en las que podrán desarrollarse intervenciones arqueológicas programadas que aporten informaciones complementarias a los resultados obtenidos en la Hospedária Beira Rio. Esperemos que estas futuras intervenciones puedan confirmar algunas de las hipótesis que ahora levantamos.

\section{BibliografiA}

Azuar Ruiz, R.(1989), Denia Islámica. Arqueología y poblamiento, Alicante.

Berti, G. y Tongiorgi, L. (1981), Il Bacini ceramici medievali delle Chiese di Pisa, Roma.

Bosch Vilá, J. (1956), Los almorávides, Tetuán.

Cavilla, F. (1992), La cerámica hispano-musulmana de Beca. Los Caños de Meca Barbate, Cádiz, Cádiz.

Cavilla, F. (2005), La cerámica almohade de la isla de Cádiz (Yazirat Qadis), Cádiz.

Constable, O. (1997), Comercio y comerciantes en la España musulmana, Barcelona.

Déléry, C. (2006), Dynamiques économiques sociales et culturelles d'al-Andalus à partir d'une étude de la céramique de cuerda seca (seconde moitié du $X^{e}$ siècle-première moitié $d u X I I I^{e}$ siècle), Tesis doctoral presentada en la Université de Toulouse II, Toulouse.

Ewert, C. (1973), "La Mezquita de Mértola (Portugal)", Cuadernos de la Alhambra, 12, 307338.

Fernandes, I. C. y Macías, S. (2011), "Islamic and Christian Medieval Archaeology", The Historiography of medieval Portugal (c. 19502010), 154-177.

Fernández Gabaldón, S.(1987), "El yacimiento de la Encarnación (Jerez de la Frontera): bases para la sistematización tipológica de la cerámica almohade en el S. O. Peninsular”, Al-Qantara, VIII, 448-474.

Fernández Sotelo, E. (1988), Ceuta medieval. Aportación al estudio de las cerámicas (s. $X-X V)$, Ceuta.

Flores Escobosa, I. (2011), "La fabricación de cerámica islámica en Almería: la loza dorada", Tudmir: Revista del Museo Santa Clara, 2, 9-28.

Flores Escobosa, I. Muñoz Martín, M. M., y Lirola Delgado, J., (1999), "Las producciones de un alfar islámico en Almería", Arqueología y territorio medieval, 6, 207-240.

Gilotte, S., Cáceres, Y. y de Juan, J. (2015), “Un 
ajuar de época almorávide procedente de Albalat (Cáceres, Extremadura)", Actas X Congresso Internacional a Cerâmica Medieval no Mediterrâneo, II, 763-776.

Gomes, R. y Gomes, M. (2001), Palácio Almoada da Alcáçova de Silves, Lisboa.

Gómez Martínez, S. (2008), Alcáçova do Castelo de Mértola 1978-2008. Trinta anos de arqueologia, Mértola.

Gómez Martínez, S. (2014), Cerámica Islámica de Mértola, Mértola.

Gómez Martínez, S. y Lopes, V. (2008), “O arrabalde de Métola e a evolução dos espaços periurbanos da cidade entre a Antiguidade e o Período Islâmico", Vipasca, 2- 2a Série, 690-697.

Gómez Martínez S. et alii (2009), "Mértola Islâmica. A madina e o arrabalde", Xelb, 9, 405-427.

Gómez Martínez, S. et alii (2015), “A cidade e o seu território no Gharb al-Andalus através da cerâmica”, Actas X Congresso Internacional a Cerâmica Medieval no Mediterrâneo, I, 19-50.

Huarte Cambra, R. y Lafuente Ibáñez, P. (2002), "La cerámica de las excavaciones de la Catedral", Magna Hispalensis (I). Recuperación de la Aljama Almohade, Granada, 403-428.

Idrīsī (1968), Description de l'Afrique et de l'Espagne par Edrīsi, trad. R. Dozy et M.J. de Goeje, Reprint, Leiden.

Inácio, I. et alii (2015), "A propósito da investigação sobre cerâmica islâmica em Portugal”, $M e$ dievalista [on line], 17 (Janeiro-Junho 2015).

http://www2.fcsh.unl.pt/iem/medievalista/MEDIEVALISTA17/isabelinacio1703.html (Consulta 02-I-2015).

Huici Miranda, A. (1959), "Un nuevo manuscrito de <al-Bayan al-Mugrib>", Al-Andalus, 24, 62-84.

Khawli, A. (2001), "Mértola islâmica: os dados dos textos árabes medievais", Museu de Mértola. Arte Islâmica, Mértola, 25-41.

Lopes, V. (2014), Mértola e o seu território na Antiguidade Tardia (Séculos IV-VIII), Tesis doctoral, Universidad de Huelva.

http://hdl.handle.net/10272/8053 (Consulta 03IX-2014).

Lopes, V., Gómez, S. y Rafael, L. (2012), Museu de Mértola. Arrabalde Ribeirinho, Mértola.

Macías, S. (2006), Mértola, o último porto do Mediterrâneo, Mértola.

Marques J. et alii (2014), Povoamento rural no troço médio do Guadiana entre o rio Degebe e a ribeira do Álamo (Idade do Ferro e perío- dos medieval e moderno). Bloco 14 - Intervenções e estudos no Alqueva, Beja.

Molina, A. y Salinas, E. (2013), "Un complejo alfarero de época islámica en la avenida de las Ollerías, Córdoba”, Arqueología de la producción en Época Medieval, Granada, 177-208.

Navarro Palazón, J. (1986a), La cerámica esgrafiada andalusí de Murcia, Madrid.

(1986b), La cerámica islámica en Murcia. Catálogo, Murcia.

Picard, C. (2000), Le Portugal musulman (VIIIeXIIIe siècle). L'Occident d'al-Andalus sous domination islamique, Paris.

Puertas, R. (1989), La cerámica islámica de cuerda seca en la Alcazaba de Málaga, Málaga.

Retuerce Velasco, M. (1998), La cerámica andalusi de la Meseta, Madrid.

Retuerce M., Hervás, M. A., y de Juan, A. (2009), "La cerámica islámica de Calatrava la Vieja y Alarcos. Nuevos hallazgos", VIII Congreso Internacional de Cerámica Medieval en el Mediterráneo, Ciudad Real, 729-758.

Rosselló Bordoy, G. (1978), Ensayo de sistematización de la cerámica árabe de Mallorca, Palma de Mallorca.

Torres, C. y Oliveira, J. C. (1987), "O criptopórtico-cisterna da Alcáçova de Mértola”, II Congreso de Arqueolgía Medieval Española, II, Madrid, 617-626.

Viguera Molins, M. J. (1994), Los reinos de Taifas. Al-Andalus en el Siglo XI, Historia de España Menéndez Pidal, VIII*, Madrid. 